\title{
Association between mast cells of different phenotypes and angiogenesis in colorectal cancer
}

\author{
LAURA V. MAURO ${ }^{1 *}$, MARIANA BELLIDO $^{2 *}$, ANA MORANDI $^{3}$, FERNANDO BONADEO $^{3}$, \\ CARLOS VACCARO ${ }^{3}$, GUILLERMO OJEA QUINTANA ${ }^{3}$, MARÍA GUADALUPE PALLOTTA ${ }^{3}$, \\ JOSÉ LASTIRI ${ }^{3}$, LYDIA I. PURICELLI ${ }^{1,4}$ and LILIA LAURÍA DE CIDRE ${ }^{2}$ \\ ${ }^{1}$ Area Investigación del Instituto de Oncología ‘Ángel H. Roffo', Av. San Martín 5481, C1417DTB Buenos Aires; \\ ${ }^{2}$ Departamento de Biodiversidad y Biología Experimental, Facultad de Ciencias Exactas y Naturales, \\ Universidad de Buenos Aires, Ciudad Universitaria, C1428EHA Buenos Aires; ${ }^{3}$ Departamentos de Clínica \\ Oncológica, Patología y Gastroenterología, Hospital Italiano, Gascón 450, C1181ACH Buenos Aires; \\ ${ }^{4}$ National Council of Scientific and Technical Research (CONICET), Argentina
}

Received June 13, 2008; Accepted September 8, 2008

DOI: $10.3892 / \mathrm{mmr}_{-} 00000047$

\begin{abstract}
It is known that mast cells proliferate in solid tumours and increase tumour angiogenesis. Nevertheless, there is no consensus regarding their role in colorectal cancer (CRC). In this study, we aimed to clarify the relationship of mast cells positive for tryptase (MCts) and tryptase-chymase (MCtcs) with microvessel density (MVD) in the intratumoral zone and the invasive edge of $80 \mathrm{CRC}$ patient tumours. We evaluated these parameters and associated their expression with clinicopathological parameters, including survival rate. Tumour sections from each patient were immunostained for tryptase to evaluate MCts, chymase to evaluate MCtcs, and CD34 to evaluate microvessel counts under x100 microscopy. The number of MCs of both phenotypes and the MVD counts were higher in the invasive edge than in the intratumoral zone $(\mathrm{p}<0.001)$. MCt numbers were higher than those of MCtcs in all Astler-Coller stages in both regions. A positive correlation between MVD and MCts or MCtcs was observed (Pearson's test $\mathrm{p}<0.001)$. Neither the number of MCs nor MVD was associated with overall survival (log rank test). However, only $8.3 \%$ of patients with low numbers of MCtcs in the invasive edge succumbed to the disease, compared to $32 \%$ with high numbers of MCtcs. Our results indicate that angiogenesis and MC hyperplasia are events which appear early during CRC development. The correlation of MC phenotypes with MVD is in agreement with the role attributed to MCs, that of angio-
\end{abstract}

Correspondence to: Dr Lilia Lauría de Cidre, Facultad de Ciencias Exactas y Naturales, Departamento de Biodiversidad y Biología Experimental, Universidad de Buenos Aires, Ciudad Universitaria, C1428EHA Buenos Aires, Argentina

E-mail: laurial@bg.fcen.uba.ar

${ }^{*}$ Contributed equally

Key words: colorectal carcinoma, mast cell tryptase, mast cell chymase, angiogenesis, immunohistochemistry genesis enhancement. Collectively, these findings suggest that screening during the early malignization of CRC can provide valuable clinical information.

\section{Introduction}

Cancer is generally viewed as the result of disrupted intracellular and intercellular homeostatic regulation. Once the homeostatic balance is lost and malignant transformation has occurred, microenvironmental factors are essential to the survival or growth of malignant cells. Tumour progression implies the ability of tumour cells to acquire an invasive phenotype in order to disorganize the extracellular matrices, reach the lymphatic and/or blood vessels, extravasate and grow in a target organ as a secondary tumour or metastasis. In this context, proteases and chemokines can play key roles in the development of metastasis, which severely affects patient prognosis and survival.

Accumulating evidence stresses the role of the tumour stroma in determining metastatic tumour behaviour. Inflammatory cells such as lymphocytes, neutrophils, macrophages or mast cells (MCs) might actually contribute to the development of malignancy (1). MCs accumulate at sites of tumour growth (2), preferentially localized around the blood and lymphatic vessels. They arise from CD34+ bone marrow precursor cells, which circulate in the blood and subsequently extravasate in connective tissues, probably recruited by tumour-derived chemoattractant factors (3). Once there, they differentiate and reach maturation in the presence of local cytokines, such as stem cell factor, IL-6 and IL-4 (4). Mature MCs express cytoplasmic granules that store proteoglycans (heparin or chondroitin sulphate), histamine, neutral proteases (chymase and/or tryptase), several cytokines and chemokines (5), allowing for the formation of new blood vessels and contributing to the development of metastases. MCs exhibit biochemical differences associated mainly with the microenvironment where they maturate and finally localize.

In humans, two different MC phenotypes are described based on the expression of proteases in their granules. MCs 
containing tryptase (MCts) are predominantly localized in the mucosa of the digestive organs and in the lung alveolar walls, while MCs containing both tryptase and chymase (MCtcs), are predominantly located in the intestinal submucosa, in the dermis of the integument and in most of the connective tissues (6). These two cell types differ in the number and type of secretory granules they contain, as well as in their responsiveness to external stimuli.

Nevertheless, MC phenotypes are not permanent, since changes in the microenvironment, such as those generated by tumour cells, induce MC activation with the consequent release of granule-associated mediators and the interconversion of one MC phenotype into the other. In addition, MCs may secrete mediators in a selective way, which can induce opposite biological responses and make the in vivo analysis of MC function difficult (3).

Two contradictory theories have been proposed in relation to the functional significance of the high number of MCs observed to be associated with tumoral processes in several experimental and human models. The first proposes that MCs may contribute to neoplastic progression by secreting proteases and cytokines, which increase tumour growth, angiogenesis and metastasis (7-9). The second suggests that MCs may impair tumour development, inducing tumour cell cytotoxicity (10) or inhibiting tumour growth and metastasis (11-15).

Colorectal cancer (CRC) is by far the most common malignancy of the gastrointestinal tract and is, without question, a 'surgical disease'. An estimated $92 \%$ of colon cancer patients and $84 \%$ of rectal cancer patients undergo surgical resection as the primary modality of treatment. The prediction of outcome for the patient is, to a large extent, based on pathologic assessment of the local disease and on other tissue-based prognostic factors in the resection specimen. However, despite the prognostic power of these parameters, the outcome for patients with similar stage tumours is heterogeneous.

Contradictory results concerning the role of MCs in the outcome of human CRC have been reported. While Shi-Yun et al (16) found the number of MCs to be directly associated with a favourable prognosis, the majority of studies, such as those of Syrjanen et al (17), Fisher et al (18) and Acikalin et al (19), have demonstrated a positive correlation between the number of MCs and tumour aggressiveness.

The aim of this study was to investigate the functional role of the MCt and MCtc populations in the intratumoral zone and the invasive edge of CRC tumours, and to study their association with the angiogenic process at different stages of CRC. We also analysed the association of MCs with the clinicopathological features of CRC, including 5-year overall survival, to determine whether MC phenotype or the number of MCs could be considered useful prognostic factors.

\section{Materials and methods}

Patients and tumours. A retrospective study was conducted using 80 paraffin-embedded CRC tumours collected between 1993 and 1999 at the 'Hospital Italiano de Buenos Aires'. All tissue specimens were obtained by surgical resection from untreated patients at initial diagnosis, and were morphologically classified according to the Astler-Coller stages. Patients were selected at random from a database including both 5-year survivors and patients who relapsed after shorter time
Table I. Characteristics of the CRC study population.

\begin{tabular}{lcccc}
\hline & & & \multicolumn{2}{c}{ Gender } \\
\cline { 4 - 5 } $\begin{array}{l}\text { Astler-Coller } \\
\text { stage }\end{array}$ & $\begin{array}{c}\text { No. } \\
(80)\end{array}$ & $\begin{array}{c}\text { Median age } \\
(\text { range })\end{array}$ & $\begin{array}{c}\text { Male } \\
(\mathrm{n}=34)\end{array}$ & $\begin{array}{c}\text { Female } \\
(\mathrm{n}=46)\end{array}$ \\
\hline A & 16 & $55(32-72)$ & 8 & 8 \\
B & 17 & $70(55-78)$ & 7 & 10 \\
C1 & 15 & $68(59-78)$ & 7 & 8 \\
C2 & 17 & $64(46-79)$ & 8 & 9 \\
D & 15 & $69(60-77)$ & 4 & 11 \\
\hline
\end{tabular}

periods. All patients, with the exception of those with stage D $\mathrm{CRC}$, underwent surgery with curative intent and presented a tumour cell-free surgical resection margin. Two patients with stage B CRC with histological factors indicative of a poor prognosis, along with patients in stages $\mathrm{C}$ and $\mathrm{D}$, received adjuvant chemotherapy after surgery $\left(5-\mathrm{FU} 400 \mathrm{mg} / \mathrm{m}^{2}\right.$ and Leukovorin $20 \mathrm{mg} / \mathrm{m}^{2}$ on days $1-5$, every 28 days). All patients who succumbed to the disease presented clear evidence of uncontrolled tumour growth at the time of death. Table I shows the characteristics of the study population.

Histology. Tumour specimens were fixed in $4 \%(\mathrm{v} / \mathrm{v})$ formaldehyde in phosphate-buffered saline (PBS) immediately after removal, and then processed to paraffin blocks. Serial transverse sections $(5 \mu \mathrm{m})$ were obtained from each case. These were placed on positively charged slides, deparaffinated and rehydrated. To evaluate general histological architecture, two of the sections were stained, one with Masson's trichrome and the other with toluidine blue (Merck, CI no. 52040), both in a $0.5 \%$ aqueous solution at $\mathrm{pH} 0.5$ for $15 \mathrm{~min}$. The remaining slides were microwaved at $800 \mathrm{~W}$ for $10 \mathrm{~min}$ in citrate buffer ( $\mathrm{pH}$ 6.0) for antigen retrieval to prepare them for immunocytochemistry.

Immunocytochemistry. After antigenicity had been recovered, slides were treated with immunocytochemical staining to identify the MCts, MCtcs and MVD. Sections were incubated overnight at $4{ }^{\circ} \mathrm{C}$ with the following commercial monoclonal primary antibodies: anti-tryptase or anti-chymase (MCA1438 diluted 1:1000 and MCA1930 diluted 1:1200; Serotec, Oxford, UK) and anti-CD34 (M7165) diluted 1:25 (Dako, Denmark). Sections were then incubated with a biotinylated anti-mouse antibody (Gibco BRL, Gaithersburg, MD, USA) diluted 1:1000 for $1 \mathrm{~h}$ at room temperature. After washing, sections were treated with the Vectastain Universal ABC kit (PK-6200, Vector Laboratories, Burlingame, CA, USA) then incubated with the chromogen 3,3'diaminobencidine (SK-4100, Vector Laboratories). Finally, they were counterstained with Mayer's haematoxylin. Negative controls, missing the first antibody, were carried out to discriminate background staining.

MC and microvessel counting methodology. CRC samples were coded and examined in a blinded manner by light microscopy. Two independent observers analysed the expression of all antigens. The presence of MCs was scored according to the number of cells with positive bright brownish staining. In slides 

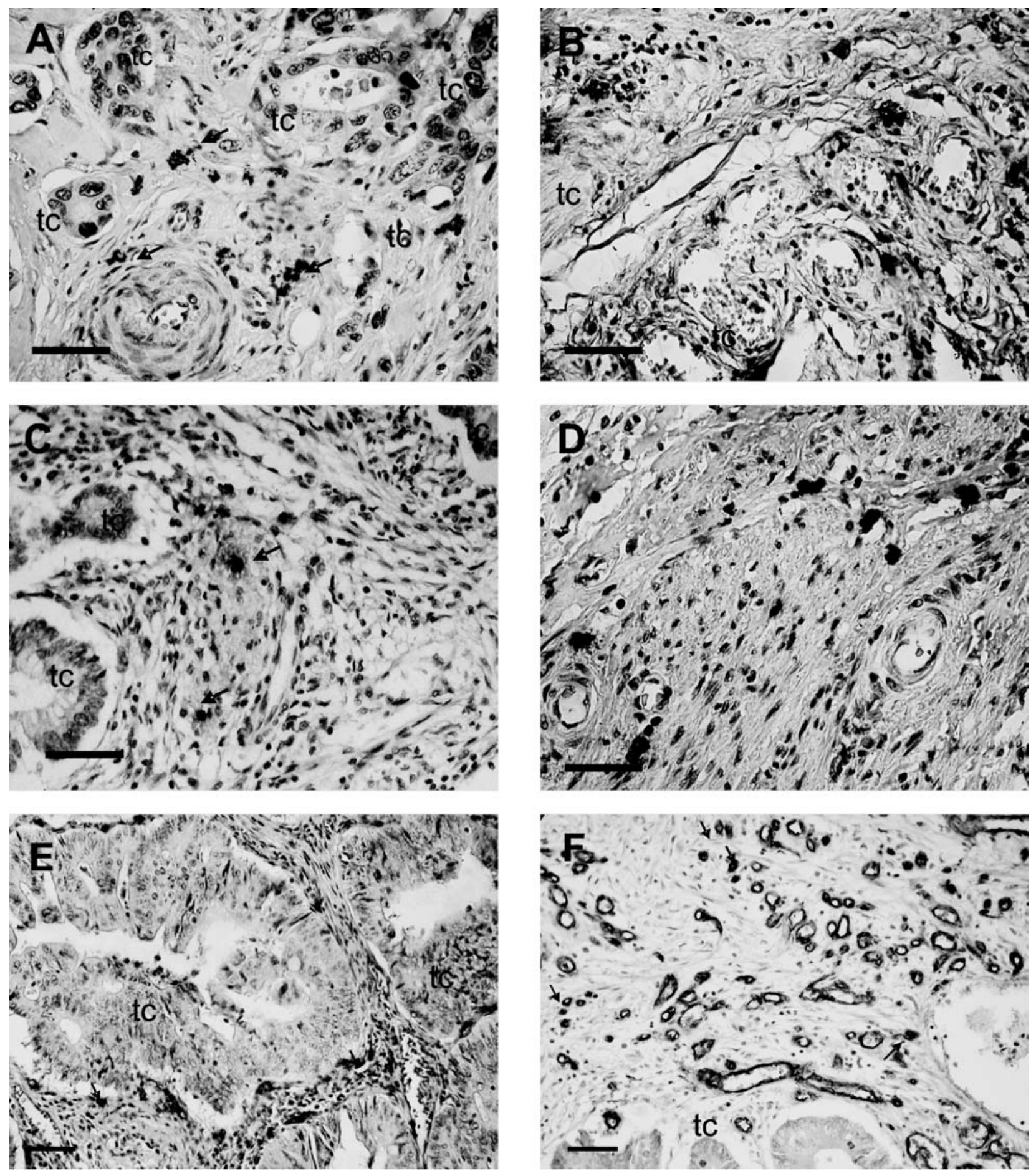

Figure 1. Representative photomicrographs of mast cell infiltration (A-D; bar, $40 \mu \mathrm{m}$ ) and microvessel density (E and F; bar, $30 \mu \mathrm{m}$ ) in human colorectal cancer. Sections were immunostained for mast cell tryptase (A and B) and mast cell chymase (C and D) and counterstained with hematoxylin. Note the extensive evidence of mast cell degranulation (arrows, A and $\mathrm{C}$ ) in the fibrous tissue adjacent to mast cells. A lower number of both mast cell phenotypes is evident in the intratumoral zone (A and C) compared to the invasive edge (B and D). Other sections of CRC were stained with anti-CD34 for microvessels (arrows) in the intratumoral zone (E) and the invasive edge (F). Note the higher density of microvessels in the invasive edge.

stained with anti-CD34, any brown-stained endothelial cells or groups of cells clearly separated from others were considered to be individual vessels. Vessels with a diameter $>45 \mu \mathrm{m}$ or with muscular walls were excluded from the analysis. Differences in the intensity of staining were not considered.

MCs and MVD were counted at X100 in five fields of $0.24 \mathrm{~mm}^{2}$ determined with the aid of a square eyepiece reticule and expressed as the number of positive counts per field. The reticule was placed at random in the intratumoral zone, while at the invasive edge it was oriented along the tumour edge. For certain statistical analyses, the values of MCs and MVD were later dichotomized to a score of 'low' or 'high' number of positive cells, employing the 25 th percentile as the cut-off value for each marker. The cut-off values for MCtcs and MCts in the intratumoral zone were 1 and 7 positive cells/ field respectively. In the invasive edge, they were 3 and 11 , respectively. The cut-off values for MVD were 13 for the intratumoral zone and 27 for the invasive edge. 


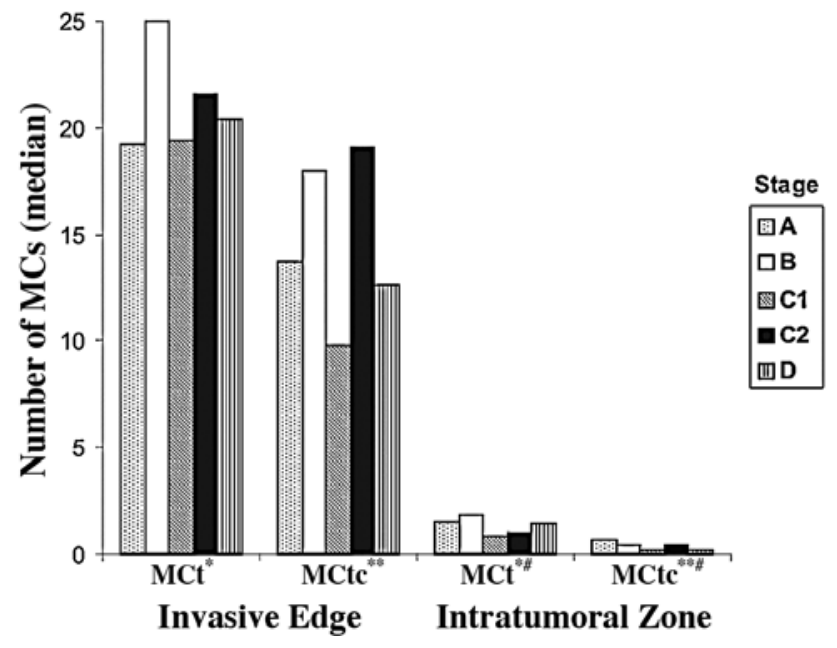

Figure 2. Number of mast cells positive for tryptase (MCt) and for chymase (MCtc) in the invasive edge (IE) and intratumoral zone (IZ) of CRC specimens. Data are presented as the median of the number of MCs of each phenotype in 5 fields of the IE and IZ of tumours according to Astler-Coller stage. ${ }^{*} \mathrm{MCt}$ in IE vs. MCt in IZ; ${ }^{* *} \mathrm{MCtc}$ in IE vs. MCtc in IZ; ${ }^{\#} \mathrm{MCt}$ vs. MCtc in the IZ. p $<0.05$ according to the Mann-Whitney test.

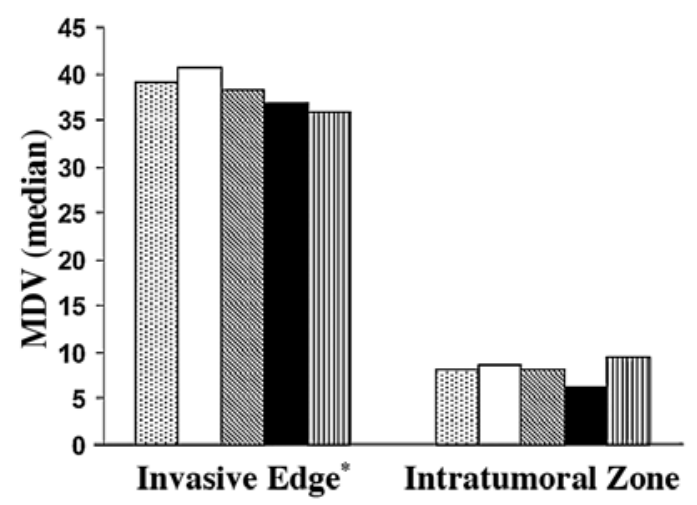

Figure 3. The microvessel count in the invasive edge and intratumoral zone in five Astler-Coller stages. ${ }^{*} \mathrm{p}<0.05$, microvessel density (MVD) from the invasive edge vs. MVD from the intratumoral zone for each Astler-Coller stage according to the Mann-Whitney test.

Statistical analysis. Differences in the number of MCs or in MVD among the groups were compared using the MannWhitney test, appropriate median tests for even skewed data.

The relationship between the expression of the different antigens and known prognostic factors in CRC was analysed as: Astler-Coller stage, grade of differentiation (G1, well differentiated; G2, moderately differentiated; G3, poorly differentiated; G4, undifferentiated), tumour location (ascending, sigmoid, rectum, and others such as descending, transverse and caecum), complications (perforation, bleeding, obstruction or multiple), type of invasion (lymphatic, venous, perineural or multiple) and the number of metastatic lymph nodes $(0,1-3$ or $>3$ ). As surgery was always successful, and as adjuvant therapy was dependent on stage (correlation $\sim 1, \mathrm{p}<0.001$ ), these variables were not included in the statistical analyses. For these analyses, the $\chi^{2}$ test and Spearman's correlation coefficients were employed. A value of $\mathrm{p}<0.05$ was considered to be a significant difference.

The Kaplan-Meier method was used to estimate overall survival, defined as the time between tumour diagnosis and

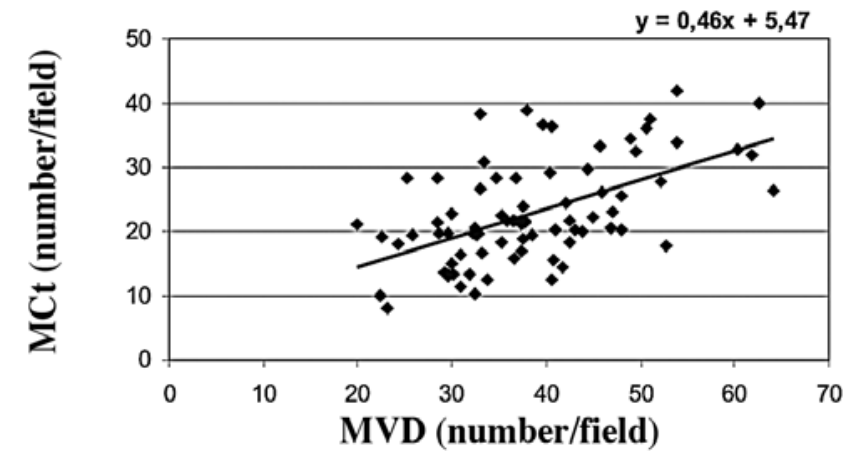

Figure 4. A significant and positive correlation between MCt (tryptase) and microvessel density (MVD) in the invasive edge.

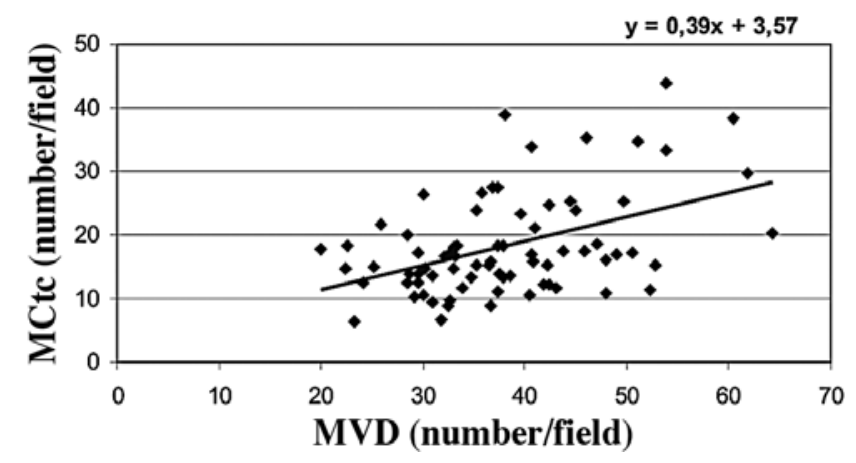

Figure 5. A significant and positive correlation between MCtc (tryptasechymase) and microvessel density (MVD) in the invasive edge.

patient death or last contact at 5 years. In univariate survival analyses, two-sided log rank tests for equality of survivor functions were used to assess the prognostic significance of different parameters on antigen positivity.

SPSSPC+ software (version 12) for Windows was used for the aforementioned analyses.

\section{Results}

Based on the fact that a large number of MCs exist at the site of solid tumours, and with the aim of understanding their functional role, we investigated the distribution of the two MC phenotypes (MCt and MCtc) in the intratumoral zone and in the invasive edge of $80 \mathrm{CRC}$ tumour biopsies from patients homogeneously distributed in the five Astler-Coller stages. Using immunocytochemical techniques, both MC phenotypes were detected by specific positivity against the chymase (MCtc) or tryptase (MCt) proteases at the cytoplasmic level.

Microvessels and MCs of both phenotypes were embedded within the connective tissue of the tumour stroma between nests of tumour cells in the intratumoral zone, and peripherally in the invasive edge. Significantly, immunocytochemicallyhighlighted intratumoral MCs appeared less heavily granulated than those in the tumour edges. Moreover, some were highly depleted of their granule content. In this case, MCs reached a diameter $\sim 6 \mu \mathrm{m}$, and only a slender cytoplasm surrounding the nucleus was distinguished. In addition, the stroma surrounding MCs exhibited a specific pale brownish color, revealing extensive evidence of MC degranulation in the extracellular matrix (Fig. 1A-D). 
Table II. Association of MCt, MCtc and MVD with clinicopathological factors in the invasive edge of CRC tumours.

\begin{tabular}{|c|c|c|c|c|c|c|}
\hline \multirow{2}{*}{$\begin{array}{l}\text { Parameter } \\
\text { Astler-Coller stage }\end{array}$} & \multicolumn{2}{|c|}{$\begin{array}{c}\mathrm{MCt} \\
\text { high/total }(\%)^{\mathrm{a}}\end{array}$} & \multicolumn{2}{|c|}{$\begin{array}{c}\text { MCtc } \\
\text { high/total }(\%)^{\mathrm{a}}\end{array}$} & \multicolumn{2}{|c|}{$\begin{array}{c}\text { MVD } \\
\text { high/total }(\%)^{\mathrm{a}}\end{array}$} \\
\hline & & & & & & \\
\hline $\mathrm{A}$ & $11 / 16$ & $(68.8)$ & $11 / 14$ & $(78.6)$ & $10 / 14$ & $(71.4)$ \\
\hline $\mathrm{B}$ & $15 / 17$ & $(88.2)$ & $16 / 17$ & $(94.1)$ & $15 / 17$ & $(88.2)$ \\
\hline $\mathrm{C} 1$ & $9 / 15$ & $(60.0)$ & $7 / 15$ & $(46.7)$ & $11 / 15$ & $(73.3)$ \\
\hline $\mathrm{C} 2$ & $16 / 17$ & $(94.1)$ & $16 / 16$ & $(100.0)$ & $12 / 17$ & $(70.6)$ \\
\hline $\mathrm{D}$ & $9 / 15$ & $(60.0)$ & $8 / 15$ & $(53.3)$ & $10 / 15$ & $(66.7)$ \\
\hline \multicolumn{7}{|c|}{ Grade of differentiation } \\
\hline G1 & $12 / 14$ & $(85.7)$ & $11 / 13$ & $(84.6)$ & $10 / 13$ & $(76.9)$ \\
\hline $\mathrm{G} 2$ & $31 / 45$ & $(68.9)$ & $30 / 43$ & $(69.8)$ & $31 / 45$ & $(68.9)$ \\
\hline $\mathrm{G} 3 / \mathrm{G} 4$ & $9 / 12$ & $(75.0)$ & $11 / 12$ & $(91.7)$ & $9 / 11$ & $(81.8)$ \\
\hline \multicolumn{7}{|l|}{ Localization } \\
\hline Ascending colon & $11 / 13$ & $(84.6)$ & $11 / 13$ & $(84.6)$ & $10 / 13$ & $(76.9)$ \\
\hline Sigmoid & $13 / 19$ & $(68.4)$ & $13 / 19$ & $(68.4)$ & $12 / 19$ & $(63.2)$ \\
\hline Rectum & $30 / 39$ & $(76.9)$ & $29 / 36$ & $(80.6)$ & $32 / 37$ & $(86.5)$ \\
\hline Other & $6 / 9$ & $(66.7)$ & $5 / 9$ & $(55.6)$ & $4 / 9$ & $(44.4)$ \\
\hline \multicolumn{7}{|l|}{ Serosal invasion } \\
\hline Yes & $40 / 53$ & $(75.5)$ & $39 / 52$ & $(75.0)$ & $39 / 53$ & $(73.6)$ \\
\hline No & $18 / 25$ & $(72.0)$ & $17 / 23$ & (73.9) & $18 / 23$ & $(78.3)$ \\
\hline
\end{tabular}

Data are expressed as the percentage of patients with a high number of positive MCs or MVD. ${ }^{a} \chi^{2}$ test (not significant).

Distribution of tryptase- and chymase-containing mast cells in CRC biopsies. Both mast cell phenotypes (MCt and MCtc) were quantified in five fields in the invasive edge and in the intratumoral zone of each biopsy, and were expressed as the median values of the number of positive counts per field. Fig. 1 shows the typical distribution of MCt, MCtc and CD34+ cells in the intratumoral zone and in the invasive edge of the CRC. The number of MCs of both phenotypes was found to be significantly higher in the invasive edge than in the intratumoral zone at all Astler-Coller stages, with increases of $\sim 15$ - and 44-fold for MCt and MCtc, respectively (Figs. 1 and 2). While no statistical difference was found between the number of MCts and MCtcs in the invasive edge, MCts were found to be significantly higher than MCtcs in the intratumoral zone (2.1- to 7-fold, according to patient stage) (Fig. 2). Correlation analysis indicated that the number of MCts and MCtcs correlated only in the tumour invasive edge (Spearman correlation coefficient $0.58, \mathrm{p}<0.001$ ).

Microvessel density in CRC biopsies. MVD was evaluated in one of the serial sections of each biopsy in fields coinciding with those where MCs were counted. MVD in the invasive edge was significantly higher than in the intratumoral zone at every Astler-Coller stage (Fig. 1E and F). As shown in Fig. 3, there were no statistically significant differences between the clinical stages of the same tumoural zone.

Relationships between MVD and MC phenotypes. Analyses were conducted to ascertain whether any correlation between
MVD and MC number and phenotype could be established. Significant positive correlations between MVD and the number of MCts or MCtcs were observed in the invasive edge (Spearman correlation test $\mathrm{r}=0.55, \mathrm{p}<0.001$ and $\mathrm{r}=0.46$, $\mathrm{p}<0.001$, respectively) (Figs. 4 and 5).

Relationships between antigen immunostainings and clinicopathological features. Possible associations of the expression of both MC phenotypes and MVD with the clinicopathological features of the CCR patients were analysed, and cases were classified as having low or high antigen expression according to the corresponding 25th percentile value. As shown in Tables II and III, the $\chi^{2}$ test showed no association between these parameters and any other of the patient clinicopathological features, including Astler-Coller stage, differentiation grade, tumour location or serosal invasion, either at the invasive edge or in the intratumoral zone. Similar results were obtained when the number of metastatic lymph nodes, the invasive type and the presence of complications at the time of diagnosis were analysed (data not shown).

Survival analysis. We studied whether MCt and MCtc numbers and MVD expression in primary CRC are related to the risk of death by comparing the survival rates of patients with tumours with high or low expression of these markers, both in the invasive edge and in the intratumoral zone. No statistically significant difference was found in terms of overall survival between patients with a low or high number of 
Table III. Association of MCt, MCtc and MVD with clinicopathological factors in the intratumoral zone of CRC tumours.

\begin{tabular}{|c|c|c|c|c|c|c|}
\hline \multirow{2}{*}{$\begin{array}{l}\text { Parameter } \\
\text { Astler-Coller stage }\end{array}$} & \multicolumn{2}{|c|}{$\begin{array}{c}\mathrm{MCt} \\
\text { positive/total }(\%)^{\mathrm{a}}\end{array}$} & \multicolumn{2}{|c|}{$\begin{array}{c}\text { MCtc } \\
\text { positive/total }(\%)^{\mathrm{a}}\end{array}$} & \multicolumn{2}{|c|}{$\begin{array}{c}\text { MVD } \\
\text { positive/total }(\%)^{a}\end{array}$} \\
\hline & & & & & & \\
\hline A & $10 / 16$ & $(62.5)$ & $10 / 14$ & (71.4) & $10 / 14$ & $(71.4)$ \\
\hline $\mathrm{B}$ & $15 / 17$ & $(88.2)$ & $15 / 17$ & $(88.2)$ & $16 / 17$ & $(94.1)$ \\
\hline $\mathrm{C} 1$ & $8 / 15$ & $(53.3)$ & $4 / 15$ & $(26.7)$ & $11 / 15$ & $(73.3)$ \\
\hline $\mathrm{C} 2$ & $16 / 17$ & $(76.5)$ & $10 / 16$ & $(62.5)$ & $8 / 17$ & $(47.1)$ \\
\hline $\mathrm{D}$ & $14 / 15$ & $(93.3)$ & $5 / 15$ & $(33.3)$ & $14 / 15$ & $(93.3)$ \\
\hline \multicolumn{7}{|c|}{ Grade of differentiation } \\
\hline G1 & $13 / 14$ & $(92.9)$ & $9 / 13$ & $(69.2)$ & $9 / 13$ & $(69.2)$ \\
\hline $\mathrm{G} 2$ & $36 / 45$ & $(80.0)$ & $24 / 43$ & $(55.8)$ & $34 / 45$ & $(75.6)$ \\
\hline G3/G4 & $7 / 12$ & $(58.3)$ & $7 / 12$ & $(58.3)$ & $9 / 11$ & $(81.8)$ \\
\hline \multicolumn{7}{|l|}{ Localization } \\
\hline Ascending colon & $10 / 13$ & $(76.9)$ & $10 / 13$ & $(76.9)$ & $12 / 13$ & $(92.3)$ \\
\hline Sigmoid & $11 / 19$ & $(57.9)$ & $8 / 19$ & $(42.1)$ & $13 / 19$ & $(68.4)$ \\
\hline Rectum & $32 / 39$ & $(82.1)$ & $24 / 36$ & $(66.7)$ & $28 / 37$ & $(75.7)$ \\
\hline Other & $7 / 9$ & $(77.8)$ & $2 / 9$ & $(22.2)$ & $6 / 9$ & $(66.7)$ \\
\hline \multicolumn{7}{|l|}{ Serosal invasion } \\
\hline Yes & $41 / 53$ & $(77.4)$ & $29 / 52$ & $(55.8)$ & $38 / 53$ & $(71.7)$ \\
\hline No & $18 / 25$ & $(72.0)$ & $15 / 23$ & $(65.2)$ & $19 / 23$ & $(82.6)$ \\
\hline
\end{tabular}

Data are expressed as the percentage of patients with a high number of positive MCs or MVD. ${ }^{a} \chi^{2}$ test (not significant).

tumoral MCs or a high or low MVD. However, of note is the fact that when the Kaplan-Meier curves for the invasive edge were analysed (Fig. 6), only $8.3 \%$ of the patients who died had low numbers of MCtcs, compared to $32 \%$ with high numbers of MCtcs.

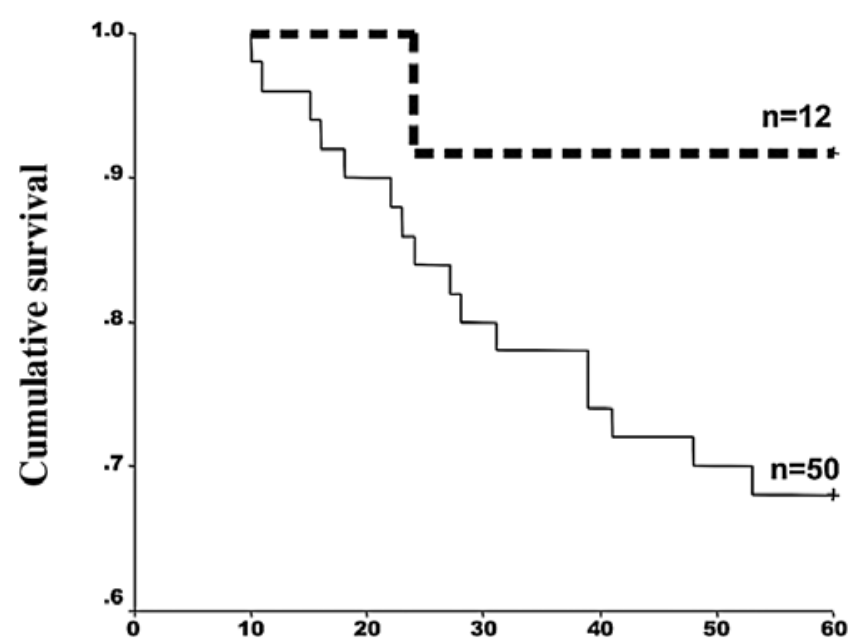

Time (months)

Figure 6. Kaplan-Meier estimation evaluating time of cumulative survival in relation with low (dotted line) or high (solid line) MCtc number in the invasive edge (log rank test, not significant).

\section{Discussion}

The prediction of outcome for patients is, to a large extent, based on pathologic assessment of the local disease and on other tissue prognostic factors in the resection specimen. However, despite the prognostic power of these parameters, outcome for patients with tumours of similar stage is heterogeneous. To more accurately individualize prognosis, additional tissue-based prognostic indicators must be investigated, for example those related to extracellular matrix remodelling as a consequence of the inflammatory cell infiltrate at the site of malignant tumours.

It has been reported that MCs are involved and deregulated in number and phenotype in immune events and in several pathologies (20-22), including cancer $(2,5,8-10,12)$. Although it is widely accepted that these cells accumulate at the site of solid tumours and are able to modulate tumour behaviour, the functional role of each MC phenotype is controversial.

In humans, MC phenotypes are distinguished by their proteinase content, which is mainly tryptase and chymase, the major secretory proteins in MC granules. Chymase, released by MCtcs, is able to regulate connective tissue homeostasis, as it degrades collagen and fibronectin and directly induces the activation of pro-matrix metalloproteinases highly involved in the invasive process (23). On the other hand, tryptase, which is released by MCs in acidic tissues such as those that are poorly vascularized, induces the cleavage of certain extracellular substrates, stimulates neighbouring MC-degranulation and is a potent indirect upregulator for neovascularization $(24,25)$. 
Our immunocytochemical results indicate that MCtcs have similar shapes and sizes, while MCts have different sizes, reaching diameters as small as $6 \mu \mathrm{m}$. These findings, together with the brown colour observed in the stroma surrounding the MCts, suggest that MCs in the vicinity of CRC cells undergo a piecemeal degranulation (reviewed in ref. 26). This is a type of regulated and selective MC chemical mediator secretion and does not imply the secretion of granule contents in toto, as happens in anaphylactic degranulation. The triggers of this selective secretion could be identified within a wide variety of cellular- and pathogen-associated products present in tumour tissues. Consequently, the deregulation of tryptase and chymase and the selective secretion of other mediators could be relevant to the invasive behaviour of tumour cells.

In this context, and with the aim of understanding the role of MCs in human CRC and investigating their putative usefulness as a tumoral marker, we examined the preferential distribution of each MC phenotype in tumours from patients without previous treatment. By scanning the intratumoral zone and the invasive edge, we observed that the number of MCs of both phenotypes was significantly higher in the invasive edge than in the intratumoral zone in all Astler-Coller stages, with MCt being the prominent phenotype. The increased number of MCs in the invasive edge may be due to MC uninterrupted renewal from stem cells leaving blood vessels and beginning their differentiation into MCs in the connective tissue while migrating towards the tumour, most probably attracted by chemokines released into the tumoral microenvironment (8). In addition, MCs are located in connective tissue surrounding tumoral nests; the smaller the amount of connective tissue present in the intratumoral zone with respect to that in the invasive edge, the lower the number of MCs recorded in a determined area will be.

The prevalence of the MCt over the MCtc phenotype has also been reported by other authors in various human cancers (27-30). This general observation is to be expected, as when resident MCtcs in the submucosa come into close proximity with tumour cells they quickly become activated by tumour factors, beginning the piecemeal degranulation and, consequently, the transition from MCtcs in the static state to reactive MCts, enhancing the MCt number. The positive correlation between the number of MCts and MCtcs in the invasive edge supports this conclusion.

Tumour growth, invasion and metastasis are dependent on the progression of neovascularization $(31,32)$. In particular, $\mathrm{MCs}$ are a source of various important angiogenic factors, including bFGF, VEGF, heparin, histamine and proteases $(33,34)$. One of our aims was to find some relationship between the MC phenotypes and MVD in CRC. We found that MVD in the invasive edge was at least 4-fold higher than in the intratumoral zone. A similar observation in $\mathrm{CRC}$ was made by Vermeulen et al (35), although they found that the intratumoral zone had only half the MVD found in the invasive edge. As the periphery of the tumour is an active zone of proliferation and invasion of tumour cells, high neovascularization aids in tumour expansion. However, although we hypothesized a positive correlation between the MVD and Astler-Coller stage, we observed a constant mean number of microvessels in all of the stages. This is in accordance with the observations of Lindmark et al (36), who affirmed that the number of microvessels is a prognostic predictor of survival independent of Dukes' stage. Our finding support the argument that angiogenesis is an early process during CRC development, as MVD is high from the first to the last Astler-Coller stage. Valuable differences in relation to tumour progression may be detected by means of angiogenesis analysis in premalignant tissues.

We found a positive and significant correlation between the MCt and MCtc phenotypes with MVD in the invasive edge. Consistent with our results, Acikalin et al (19) made the same observation, although without discriminating between the two MC phenotypes. It may be hypothesized that an increase in MCtcs increases the number of MCts when the former degranulates and consequently changes the phenotype. This fact suggests that both MCts and MCtcs can, by different methods, upregulate CRC angiogenesis.

As there is no consensus to date concerning the role of MCs and MVD in the progression of CRC $(17,18,37)$, we analysed a group of CRC patients, including individuals with low-stage CRC undergoing homogeneous therapies, with a high quality clinical date and a follow-up time of 5 years.

We were unable to demonstrate any relationship between the number of MCts or MCtcs and MVD and the main clinicopathological parameters in CRC pathology. Kaplan-Meier survival curves in patients with tumours with high or low expression of MCs or MVD, both in the invasive edge or in the intratumoral zone, showed no statistical differences. However, it is noteworthy to remark that only $8.3 \%$ of patients with low numbers of MCtcs succumbed to the disease, compared to $32 \%$ with high numbers of MCtcs, when the Kaplan-Meier curves for the invasive edge were analysed. This observation probably indicates that this MC phenotype could be an emerging clinical marker. Consequently, extending this study to include a larger patient sample could have important results. Moreover, we confirmed that the overall survival of our CRC subpopulation could be predicted by stage, the number of metastatic lymph nodes, and the occurrence of vascular-neural invasion, representatively supporting our data (data not shown).

In agreement with McShane et al (38), we believe that it is imperative to understand the reasons why multiple studies of the same marker lead to different conclusions. A variety of problems have been cited to explain these discrepancies, such as general methodological differences, e.g. those implemented for counting the structures of interest. Poor study designs, assays that are not standardized or that lack reproducibility, and inappropriate or misleading statistical analyses that are often based on too small a sample size are also factors that lead to unmeaningful results.

In conclusion, our findings regarding the correlation between the presence of MCs and MVD in the invasive edge of CRC support the hypothesis that both MC phenotypes play a significant role in tumour progression. Moreover, the observation that a low number of MCtcs in the invasive edge is indicative of a favourable overall patient survival suggests the necessity of additional studies to determine the real value of MCtcs as a prognostic factor in CRC pathology. Although MCs may play a beneficial role in patients during the initial period of carcinogenesis by inhibiting tumour development (14), if a tumour wins, MCs may contribute to its progression. In such cases, therapy to inhibit the action of MCs may support a favourable patient outcome. 


\section{Acknowledgements}

The present work was supported by grant no. X-122 from the Universidad de Buenos Aires. We are thankful to Martín Krasnapolski for assistance with figure design.

\section{References}

1. Naukarinen A and Syrijänen K: Quantitative immunohistochemical analysis of mononuclear infiltrates in breast carcinomas Correlation with tumour differentiation. J Pathol 160: 217-222, 1990 .

2. Lauria de Cidre L and Sacerdote de Lustig E: Mast cell kinetics during tumor growth. Tumour Biol 11: 196-201, 1990.

3. Conti P, Castellani ML, Kempuraj D, Salini V, Vecchiet J, Tetè S, Mastrangelo F, Perrella A, De Lutiis MA, Tagen M and Theoharides TC: Role of mast cells in tumor growth. Ann Clin Lab Sci 37: 315-322, 2007.

4. Shiohara M and Koike K: Regulation of mast cell development. Chem Immunol Allergy 87: 1-21, 2005.

5. Norrby K: Mast cells and angiogenesis. APMIS 110: 355-371, 2002.

6. Irani AM and Schwartz LB: Human mast cell heterogeneity. Allergy Proc 15: 303-308, 1994.

7. Norrby K and Wooly D: Role of mast cells in mitogenesis and angiogenesis in normal tissue and tumour tissue. Adv Biosci 89: 71-116, 1993 .

8. Yano H, Kinuta M, Tateishi H, Nakano Y, Matsui S, Monden T, Okamura J, Sakai $M$ and Okamoto $\mathrm{S}$ : Mast cell infiltration around gastric cancer cells correlates with tumour angiogenesis and metastasis. Gastric Cancer 2: 26-32, 1999.

9. Elpek GO, Gelen T, Aksoy NH, Erdogan A, Dertsiz L, Demircan A and Keles N: The prognostic relevance of angiogenesis and mast cells in squamous cell carcinoma of the oesophagus. J Clin Pathol 54: 940-944, 2001.

10. Ghiara P, Boraschi D, Villa L, Scapigliati G, Taddei C and Tagliabue A: In vitro generated mast cells express natural cytotoxicity against tumor cells. Immunology 55: 317-324, 1985.

11. Aaltomaa S, Lipponen P, Papinaho S and Kosma VM: Mast cells in breast cancer. Anticancer Res 13: 785-788, 1993.

12. Bertolesi GE, Lauría de Cidre L and Eijan A: Growth inhibition in vitro of murine mammary adenocarcinoma cells by heparin and chemically modified heparins. Tumor Biol 15: 275-283, 1994.

13. Bertolesi GE, Lauría de Cidre L, Sacerdote de Lustig E and Eiján A: Heparin receptors in two murine mammary adenocarcinomas with different metastatic ability. Cancer Lett 90: 123-131, 1995.

14. Lauria de Cidre L, Eijan AM, Bertolesi G, Isturiz M and Sacerdote de Lustig E: Influence of mast cells on two murine mammary adenocarcinomas. Tumour Biol 17: 345-353, 1996.

15. Tomita M, Matsuzaki Y and Onitsuka T: Correlation between mast cells and survival rates in patients with pulmonary adenocarcinoma. Lung Cancer 26: 103-108, 1999.

16. Shi-Yun T, Fan Y, Luo HS, Shen ZX, Guo Y and Zhao LJ: Prognostic significance of cell infiltrations of immunosurveillance in colorectal cancer. World J Gastroenterol 11: 1210-1214, 2005.

17. Syrjanen KJ and Hjelt LH: Host-host relationships in colorectal carcinoma. Dis Colon Rectum 21: 29-36, 1978.

18. Fisher ER, Paik SM, Rockette H, Jones J, Caplan R and Fisher B: Prognostic significance of eosinophils and mast cells in rectal cancer: findings from the National Surgical Adjuvant Breast and Bowel Project (protocol R-01). Hum Pathol 20: 159-163, 1989.
19. Acikalin MF, Oner Ü, Topcu B, Yasar B, Kiper H and Colak E: Tumour angiogenesis and mast cell density in the prognostic assessment of colorectal carcinomas. Dig Liver Dis 37: 162-169, 2005

20. Friend D, Ghildyal N, Gurish M, Hunt J, Hu X, Austen KF and Stevens RL: Reversible expression of tryptases and chymases in the jejunal mast cells of mice infected with Trichinella spiralis. J Immunol 160: 5537-5545, 1998.

21. Gruber BL: Mast cells in the pathogenesis of fibrosis. Curr Rheumatol Rep 5: 147-153, 2003.

22. Wang HW, Tedla N, Hunt JE, Wakefield D and McNeil HP Mast cell accumulation and cytokine expression in the tight skin mouse model of scleroderma. Exp Dermatol 14: 295-302, 2005.

23. Tchougounova E Lundequist A, Fajardo I, Winberg JO, Abrink M and Pejler G: A key role for mast cell chymase in the activation of pro-matrix metalloprotease- 9 and pro-matrix metalloprotease-2. J Biol Chem 280: 9291-9296, 2005.

24. Paine V and Kam PCA: Mast cell tryptase: a review of its physiology and clinical significance. Anesthesia 59: 695-703, 2004.

25. Urata H, Boehm KD, Philip A, Kinoshita A, Gabrovsek J, Bumpus FM and Husain A: Cellular localization and regional distribution of an angiotensin II-forming chymase in the heart. J Clin Invest 91: 1269-1281, 1993.

26. Dvorak AM: Ultrastructural studies of human basophils and mast cells. J Histochem Cytochem 53: 1043-1070, 2005.

27. Kankkunen JP, Harvima IT and Naukkarinen A: Quantitative analysis of tryptase and chymase containing mast cells in benign and malignant breast lesions. Int J Cancer 72: 385-388, 1997.

28. Beil WJ, Füreder W, Wiener H, Grossschmidt K, Maier U, Schedle A, Bankl HC, Lechner K and Valent P: Phenotypic and functional characterization of mast cells derived from renal tumour tissues. Exp Hematol 26: 158-169, 1998.

29. Ribatti D, Vacca A, Marzullo A, Nico B, Ria R, Roncali L and Dammacco F: Angiogenesis and mast cell density with tryptase activity increase simultaneously with pathological progression in B-cell non-Hodgkin's lymphomas. Int J Cancer 85: 171-175, 2000.

30. Cabanillas-Saez A, Schalper JA, Nicovani SM and Rudolph MI: Characterization of mast cells according to their content of tryptase and chymase in normal and neoplastic human uterine cervix. Int J Gynecol Cancer 12: 92-98, 2002.

31. Folkman $\mathrm{J}$ : What is the evidence that tumours are angiogenesis dependent? J Natl Cancer Inst 82: 4-6, 1990.

32. Castro G Jr, Puglisi F, De Azambuja E, El Saghir NS and Awada A: Angiogenesis and cancer: a cross-talk between basic science and clinical trials (the 'do ut des' paradigm). Crit Rev Oncol Hematol 59: 40-50, 2006

33. Sawatsubashi M, Yamada T, Fukushima N, Mizokami H, Tokunaga $\mathrm{O}$ and Shin T: Association of vascular endothelial growth factor and mast cells with angiogenesis in laryngeal squamous cell carcinoma. Virchows Arch 436: 243-248, 2000.

34. Ch'ng S, Wallis RA, Yuan L, Davis PF and Tan ST: Mast cells and cutaneous malignancies. Mod Pathol 19: 149-159, 2006.

35. Vermeulen PB, Verhoeven D, Fierens H, Hubens G, Goovaerts G, van Marck E, De Bruijn EA, van Oosterom AT and Dirix LY: Microvessel quantification in primary colorectal carcinoma: an immunohistochemical study. Br J Cancer 71: 340-343, 1995.

36. Lindmark G, Gerdin B, Sundberg Ch, Páhlman L, Bergström R and Glimelius B: Prognostic significance of the microvascular count in colorectal cancer. J Clin Oncol 14: 461-466, 1996.

37. Pretlow TP, Keith EF, Cryar AK, Bartolucci AA, Pitts AM, Pretlow TG, Kimball PM and Boohaker EA: Eosinophil infiltration of human colonic carcinomas as a prognostic indicator. Cancer Res 43: 2997-3000, 1983.

38. McShane L, Altman D, Sauerbrei W, et al: Statistics Subcommittee of the NCI-EORTC Working Group on Cancer Diagnostics. 1180 Commentary. J Natl Cancer Inst 97: 1180-1184, 2005. 